\title{
The effect of verbal elaborations on memory in young and older adults
}

\author{
KATIE E. CHERRY \\ Louisiana State University, Baton Rouge, Louisiana \\ DENISE C. PARK and DAVID A. FRIESKE \\ University of Georgia, Athens, Georgia \\ and \\ RENEE L. ROWLEY \\ Louisiana State University, Baton Rouge, Louisiana
}

\begin{abstract}
The Stein paradigm was used to examine the circumstances under which verbal elaborations enhance memory in young and older adults. Subjects studied target adjectives that were embedded in one of three sentence contexts that varied in elaboration of the subject-adjective relationship: (1) nonelaborated base sentences; (2) base sentences with semantically consistent, but arbitrary verbal, elaborations; and (3) base sentences with explanatory verbal elaborations that clarified the significance of the subject-adjective relationship. The presence of the elaborations was varied at encoding and retrieval, and cued recall of the target adjectives was tested with incidental and intentional learning procedures. In Experiments $1 \mathrm{~A}$ and $1 \mathrm{~B}$, explanatory elaborations at encoding and retrieval yielded the largest memorial facilitation for both young and older adults, and the benefit was comparable for the incidental and intentional learning measures. In Experiment 2, age-related differences in recall were minimal with explanatory elaborations at encoding and retrieval, but larger age differences occurred in the nonelaborated comparison conditions. In Experiment 3, explanatory elaborations present at encoding but not at retrieval enhanced recall when the original Stein stimuli were used, but not with the present stimuli. The implications of these results with regard to the mnemonic efficacy of verbal elaborations for young and older adults are discussed.
\end{abstract}

It is generally agreed that learning and retention can be improved by providing elaborative information that clarifies the significance of conceptual relationships in written discourse. Numerous reports in the general experimental literature have shown that verbal elaborations enhance memory for written material (Franks et al., 1982; Stein \& Bransford, 1979; Stein, Bransford, Franks, Owings, et al., 1982; Stein, Bransford, Franks, Vye, \& Perfetto, 1982). These findings are particularly important for the study of adult cognition, since verbal elaborations could be used as a memory aid for older adults who experience declines in many component processes of cognition (Salthouse, 1991). Despite its importance, the mnemonic efficacy of verbal elaborations for older adults has been examined in only a few studies (see Hashtroudi, Parker, Luis, \& Reisen, 1989; Rankin \& Collins, 1985).

Stein and his associates have found that elaborative phrases that clarify the significance of confusing conceptual relationships have a positive effect on memory for

Portions of this research were supported by National Institute on Aging Grant R01AGO60625 to the second author. We wish to thank Alicia Benoit and Ashlie Segura for their help with testing in Experiments 2 and 3. Address all correspondence to K. E. Cherry, Department of Psychology, Louisiana State University, Baton Rouge, LA 70803-5501. sentential information in college students. Their research has shown that explanatory elaborations improve the recall of key concepts in sentences more than semantically consistent, arbitrary elaborations and nonelaborated sentence contexts do, and these results have been replicated in numerous reports (e.g., Stein \& Bransford, 1979; Stein, Brock, Ballard, \& Vye, 1987; Stein, Littlefield, Bransford, \& Persampieri, 1984; Stein, Morris, \& Bransford, 1978). Consequently, Stein and his colleagues have suggested that intervention strategies that reduce the inherent arbitrariness of new information in an unfamiliar knowledge domain could be used in educational settings, underscoring the potential applied significance of their findings (Bransford et al., 1982; Stein et al., 1984).

Stein et al.'s (Stein \& Bransford, 1979; Stein et al., 1987; Stein et al., 1984; Stein et al., 1978) findings, demonstrating the positive effect of verbal elaborations on memory, are particularly relevant to the study of cognitive aging. The environmental support view of memory aging (Craik, 1983, 1986) suggests that elderly persons have difficulty with memory tasks that require a substantial amount of self-initiated processing, owing to age-related declines in processing resources for these operations. Thus, older persons may benefit more than younger adults from contextual information in the memory environment 
that supports task-appropriate mental processes and reduces the demand for self-initiated processing at encoding and retrieval. Craik's environmental support hypothesis (Craik, 1986; Craik \& Jennings, 1992) would predict that older adults may have particular difficulty with nonelaborated sentence contexts that would require effortful, selfinitiated processing to encode and retrieve, whereas older people might benefit more than younger persons from explanatory elaborations that clarify otherwise confusing sentences and reduce the demand for effortful, selfinitiated processing activity. The Stein paradigm permits a test of the environmental support hypothesis along two dimensions, since the support for subjects' encoding and retrieval operations can be varied both quantitatively (presence/absence of verbal elaborations) and qualitatively (arbitrary/explanatory elaborations). Evidence in favor of the environmental support hypothesis would be reflected in a significant age $\times$ elaboration condition interaction, where older adults would show a relatively greater memorial benefit from the explanatory elaborations present during encoding and retrieval than younger adults would. Such a finding would be consistent with those of Bäckman and Karlsson (1986), Cherry and Park (1991), Craik, Byrd, and Swanson (1987), and Shaw and Craik (1989), who have substantiated the environmental support hypothesis in other verbal recall paradigms.

In a few studies, the effectiveness of verbal elaborations for older adults in a verbal elaboration paradigm has been examined, but the outcomes have been mixed. Rankin and Collins (1985) presented young and older adults with base, imprecisely elaborated, and precisely elaborated sentences for study. They found that free recall of target nouns did not vary as a function of type of elaboration. Cued recall improved more with precise elaborations than with the imprecise and base sentence contexts for both age groups, confirming the benefit of explanatory elaborations for older adults. In contrast, Hashtroudi et al. (1989) found that experimenter-provided explanatory elaborations enhanced cued recall of target adjectives for the young, replicating Stein's earlier work, but recall did not vary as a function of experimenter-provided elaborations for the old. Both young and older people benefited most from self-generated elaborations in Hashtroudi et al.'s study. A number of methodological and procedural differences exist between Rankin and Collins's and Hashtroudi et al.'s reports that may be responsible for their contrasting outcomes. For example, Rankin and Collins presented the elaborations at encoding and retrieval, so that it is not clear whether the elaborations affected the older persons' encoding operations, retrieval operations, or both in their study. In contrast, Hashtroudi et al. presented the elaborations at encoding but not at retrieval: only the base sentence contexts served as prompts for recall, after Stein's original procedures. Thus, older adults' failure to benefit from the experimenter-provided elaborations at encoding may have been due to the confounding of study/test contexts in Hashtroudi et al.'s study.

We designed the present studies in order to examine the effect of verbal elaborations on adult age differences in memory within a framework that examines the independent effects of elaborations on subjects' encoding and retrieval processes. The separation of encoding from retrieval is of particular interest with older subjects. Elderly persons may fail to elaborate study material spontaneously in ways that would promote successful remembering on their own initiative (Craik, 1983, 1986; Perlmutter \& Mitchell, 1982; Smith, 1980). Thus, explanatory elaborations at encoding may enhance older persons' encoding operations to a greater extent than their younger counterparts. Older adults are also thought to have particular difficulty when long-term memory tests require them to direct their retrieval processes on their own initiative (see Craik, 1983, 1986; Craik et al., 1987; Rabinowitz, Craik, \& Ackerman, 1982), so that older adults might be expected to benefit more than younger adults from elaborations present at retrieval. In sum, the positive effect of explanatory elaborations on memory in older adults should be amplified when the elaborations are present at encoding and retrieval, in line with the environmental support hypothesis.

There are conflicting opinions on the mnemonic efficacy of experimenter-provided verbal elaborations. Pressley, McDaniel, Turnure, Wood, and Ahmad (1987) have argued that the conditions under which the explanatory elaboration effect is obtained may be quite limiting, and limited to conditions of incidental learning used in the Stein studies. Pressley et al. varied intentionality (intentional vs. incidental learning), the nature of the elaborations (subject-generated vs. experimenter-provided), and the sentence context (base, explanatory). With an incidental learning task, Pressley et al. found that explanatory elaborations had only a modest effect on performance, relative to the base sentence condition. With an intentional learning task, there was no evidence of a memorial advantage of experimenter-provided explanatory elaborations, although subjects' self-generated elaborations did improve recall (see Hashtroudi et al., 1989, for a similar result). In contrast to the Stein results, in which explanatory elaborations enhanced memory, Pressley et al.'s report implies that the mnemonic value of experimenterprovided explanatory elaborations may be slight, and limited to conditions in which learning is incidental. In the present research, incidental and intentional learning procedures are used to provide further evidence on this issue.

The main objectives of the present research were to examine the influence of verbal elaborations on recall in older adults, and to systematically outline the conditions under which elaborations are most effective as memory support. Specifying the parameters that may control the effectiveness of elaborations is important, since prior research has yielded inconsistent outcomes that may be due to the different task demands and materials used in these studies (e.g., Pressley et al., 1987). Taken together, the results of the present studies should show whether explanatory elaborations enhance recall as Stein and his colleagues have argued, or whether they provide further evidence that the effect is fragile and unreliable, as Pressley et al. suggested. The present results should also show whether elderly persons derive a relatively greater bene- 
fit from explanatory elaborations than younger adults do, as the environmental support hypothesis predicts. Such a finding would have important implications for everyday memory practice, and may suggest a direction for interventions designed to promote learning and retention of verbal information in older people. To summarize, in Experiments $1 \mathrm{~A}$ and $1 \mathrm{~B}$, incidental and intentional learning procedures were used to replicate and extend Stein's earlier findings. The presence of elaborations at retrieval was also manipulated in these studies. In Experiment 2, the presence of explanatory elaborations was factorially varied at encoding and retrieval to assess the independent effects of elaborations on young and older persons' encoding and retrieval processes. In Experiment 3, Stein et al.'s stimuli and procedures were factorially crossed with the present stimuli and procedures to isolate the locus of the explanatory elaboration effect reported by Stein and his colleagues.

\section{EXPERIMENT 1A}

In Experiment $1 \mathrm{~A}$, young and older adults studied one of three sentence contexts (base sentences alone, with arbitrary elaborations, or with explanatory elaborations), using an incidental learning procedure. The orienting task required subjects to judge the ease of visualizing the referents of the sentences. This task was chosen to foster a more elaborative and integrative encoding of the target adjectives and their respective sentence contexts. Half the subjects were given the complete sentence contexts as a cue for recall of the target adjectives (i.e., elaborations present during encoding were reinstated at retrieval). The other half were given only the base sentences as prompts for recall.

\section{Method \\ Participants. In all, 120 subjects participated in the study. There were 60 University of Georgia undergraduates $(M=19.2$ years, $S D=2.0$ years) and 60 community-dwelling older adults $(M=$ 67.9 years, $S D=5.8$ years). Younger subjects participated in ex- change for credit to meet the psychology course requirement. The older adults were recruited from a condominium resort in a North Florida community. The older adults were paid $\$ 5.00$ for partici- pation. The subjects' responses to a demographic questionnaire that contained a subset of self-perceived health questions (OARS; see Duke University, 1975) indicated that most subjects, young and old, rated their health as "good" to "excellent" and only 4 young adults and 7 older adults rated their health as "fair." Gardner and Monge's (1977) 30 Point Word Familiarity Survey was given as a measure of verbal ability. The older adults' mean verbal score (17.4) was significantly greater than the younger adults' score (13.5) $[t(118)=3.917, p<.001]$, replicating the well-documented find- ing in the cognitive aging literature of age differences favoring older adults in verbal ability. All subjects possessed 20/30 corrected visual acuity or better.}

Stimulus materials. The total stimulus set comprised three sets of 28 sentences (base, arbitrary elaboration, and explanatory elaboration sentence sets), similar to the 10 original sentences in Stein et al. (see Appendix A). We constructed our own stimuli for the purpose of enlarging the total stimulus set, as did Pressley et al. (1987) and Rankin and Collins (1985). The base sentences used in the present research contained a subject-adjective relationship that was inherently arbitrary (e.g., the grimacing man held the cheese). That is, there is no obvious reason why the man should be grimacing, given the base sentence context. For each base sentence, an arbitrary and explanatory verbal elaboration was constructed. The arbitrary elaborations were designed to be semantically consistent with the base sentence context, but did not clarify the confusing subject-adjective relationship (e.g., the grimacing man held the cheese and reached for a cracker). The explanatory elaborations were designed to explain the subject-adjective relationship, and thus clarify the significance of the target adjective (e.g., the grimacing man held the cheese while the mousetrap sprang on his finger). The retrieval sentences were identical to the acquisition sentences, except that the adjectives were replaced by a blank line. The acquisition and test sentences were presented individually with a Kodak carousel slide projector at an 8 -sec rate.

Design. The design was a 2 (age) $\times 5$ (elaboration condition) between-group factorial. This design was chosen to permit the inclusion of a control condition with base sentences at encoding and at retrieval. For convenience in exposition, low retrieval support refers to the conditions in which the arbitrary or explanatory elaborations were present only at encoding, and the base sentences were presented as retrieval cues. High retrieval support refers to the conditions in which the arbitrary or explanatory elaborations were present at encoding and retrieval. Thus, age (young, old) was factorially crossed with elaboration condition (base sentences only, arbitrary elaborations-low retrieval support, explanatory elaborationslow retrieval support, arbitrary elaborations-high retrieval support, explanatory elaborations-high retrieval support), resulting in 10 between-group conditions. Twelve subjects were tested in each between-group condition.

Procedure. The subjects were tested in small groups of up to four. They were told that the study was concerned with adult age differences in sentence comprehension, after Stein et al. (1987). As a result of initial pilot testing with elderly adults, we chose an imagery rating orienting task over the original Stein sentence comprehensibility rating task in order to elevate older adults' recall performance. At the beginning of the testing session, the subjects were trained on the imagery rating task, which enhanced their attention to the subject-adjective relationship. They were told to read each sentence first, generate a visual image of the referents of the sentence, and rate how easy the sentence was to visualize on a scale of $1-5(1=$ very easy, $5=$ very difficult to image $)$. Four practice sentences were shown in turn, and the subjects made their imagery judgments on a prepared sheet. The acquisition sentences were presented next. The experimenter read each sentence aloud as it was shown, as in Stein et al.'s (1987) procedure, and the subjects recorded their responses on a prepared sheet. Two acquisition orders were used equally often across subjects.

Following acquisition, a 2 -min distractor task was given, in which subjects continuously subtracted 7 from 500 on a separate page. The cued recall phase occurred next. The subjects were presented with the same sentences (less the target adjectives) in a new order, with or without the verbal elaborations, depending on the experimental condition. They were told to read each sentence first, try to recall the missing adjective, and record the answer on a response sheet. The verbal ability measure, demographic questionnaire, and vision test were then given, and debriefing followed

\section{Results}

For each subject, the number of adjectives correctly recalled was counted and expressed as a proportion of the total number of items presented (28). Proportion scores were entered into an analysis of variance (ANOVA) with age and elaboration condition as factors. Unless other- 
wise indicated, all reported effects in this article were significant at the .01 level, and all post hoc comparisons were made using Tukey's HSD test.

This analysis yielded significant main effects of age $\left[F(1,110)=59.09, M S_{\mathrm{e}}=.02\right]$ and elaboration condition $\left[F(4,110)=25.89, M S_{\mathrm{e}}=.02\right]$. Young adults $(.35)$ recalled more adjectives than did older adults (.14), and recall was highest in the explanatory elaborations-high retrieval support condition (.51), followed by arbitrary elaborations-high retrieval support (.23), explanatory elaborations-low retrieval support (.19), base sentence only (.17), and arbitrary-low retrieval support (.11) conditioning. Pairwise comparisons indicated that the proportion of items recalled in the explanatory elaborations-high support condition was significantly greater than that in each of the four comparison conditions, and the arbitrary-high support condition significantly exceeded the arbitrary-low support condition. None of the remaining pairwise comparisons approached significance. The number of intralist and extralist intrusions were too low to warrant analysis.

Inspection of Table 1 indicates that the older adults' performance is approaching floor in most of the comparison conditions. To check the reliability of the results described above, a one-way ANOVA was conducted on the recall scores for the younger adults. The main effect of elaboration condition was significant $\left[F(4,55)=10.88, M S_{\mathrm{e}}=\right.$ .03 ] , and the same pattern of significant pairwise differences was obtained. Thus, the reported effects do not appear to be the result of floor effects in the older adults' data. For the young, recall in the explanatory elaborationslow support condition (.29) was significantly greater than the arbitrary elaborations-low support condition (.16) $[t(22)=2.68]$. Similarly, the explanatory elaborationshigh support condition (.61) significantly exceeded the arbitrary elaborations-high support condition $(.37)[t(22)=$ 2.86]. These results confirm Stein's argument that explanatory elaborations enhance memory more than arbitrary elaborations. However, the finding that recall in the explanatory elaborations-low support group (.29) was virtually identical to that in the base sentence control (.30) $[t(22)=.043, p=.9]$ is at odds with the earlier Stein reports (Stein \& Bransford, 1979; Stein et al., 1984; Stein et al., 1978). Our results suggest that the reinstatement of the elaborations at retrieval may be a critical factor for elaborations to enhance memory.

Table 1

Mean Proportion of Adjectives Recalled, With Standard Deviations, as a Function of Age and Elaboration Type in Experiment $1 \mathrm{~A}$

\begin{tabular}{|c|c|c|c|c|c|c|}
\hline \multirow[b]{3}{*}{ Age } & \multirow{2}{*}{\multicolumn{2}{|c|}{ Base }} & \multicolumn{4}{|c|}{ Elaboration Type } \\
\hline & & & \multicolumn{2}{|c|}{ Arbitrary } & \multicolumn{2}{|c|}{ Explanatory } \\
\hline & $M$ & $S D$ & $M$ & $S D$ & $M$ & $S D$ \\
\hline \multicolumn{7}{|c|}{ Low Retrieval Support } \\
\hline Young & .30 & .20 & .16 & .11 & .29 & .13 \\
\hline Old & .05 & .07 & .06 & .11 & .08 & .08 \\
\hline \multicolumn{7}{|c|}{ High Retrieval Support } \\
\hline Young & & & .37 & .19 & .61 & .21 \\
\hline Old & & & .09 & .07 & .41 & .21 \\
\hline
\end{tabular}

To further examine the effects of type of elaboration at encoding and the presence of support at retrieval on memory, a follow-up analysis was conducted to permit the independent effects of these variables to emerge. In this ANOVA, the base sentence condition was excluded, resulting in a completely crossed factorial design with age (young vs. old), elaboration type (arbitrary vs. explanatory), and retrieval support (low vs. high retrieval support) as between-group factors. The results of this analysis replicated the preceding analyses. The main effects of age, elaboration type, and retrieval support were significant. Younger adults $(.36)$ recalled more adjectives than did older adults $(.16)\left[F(1,88)=42.93, M S_{\mathrm{e}}=.02\right]$. Explanatory elaborations $(.35)$ enhanced performance more than arbitrary elaborations did $(.17)[F(1,88)=33.86$, $M S_{\mathrm{e}}=.02$ ], and recall was greater in the high support conditions (.37) than in the low support conditions (.15) $\left[F(1,88)=52.37, M S_{\mathrm{e}}=.02\right]$. The elaboration type $\times$ retrieval support interaction effect was also significant $\left[F(1,88)=10.73, M S_{\mathrm{e}}=.02\right]$. Analyses of simple main effects confirmed that recall was significantly greater in the explanatory elaborations condition (.51) than in the arbitrary elaborations condition (.23), with high retrieval support $(p<.01)$. However, with low retrieval support, the means for the explanatory and arbitrary elaboration conditions did not significantly differ $(p>.05)$. These means, in order, were .19 and .11 .

\section{Discussion}

Experiment 1A yielded three main findings. First, in the conditions most similar to those in Stein et al.'s studies (i.e., young adults in the low support conditions), explanatory elaborations at encoding enhanced memory more than did the arbitrary elaborations, in line with Stein et al.'s reports (Stein \& Bransford, 1979; Stein et al., 1984; Stein et al., 1978). Performance in the explanatory (low support) condition did not significantly differ from base sentence condition, which conflicts with Stein et al. (Stein \& Bransford, 1979; Stein et al., 1984; Stein et al., 1978). The discrepant outcomes may be due to differences in the materials and procedure of the present study and Stein et al.'s studies. This issue will be addressed after Experiment 3's results are reported. One could also question whether the base sentence condition is an appropriate control for comparisons with the low support elaboration conditions, since recall in the base sentence condition is confounded by encoding specificity effects (see Tulving \& Thompson, 1973). That is, the encoding and retrieval contexts were mismatched in the arbitrary and explanatory low support conditions, but not in the base sentence condition. Context reinstatement effects may have augmented recall in the base sentence condition. Consequently, the advantage of explanatory elaborations present only at encoding over base sentence contexts was not obtained.

Second, the follow-up analysis indicated that elaboration condition interacted with retrieval support: explanatory elaborations improved performance more than arbitrary elaborations when the elaborations were reinstated at retrieval, but the arbitrary and explanatory low retrieval sup- 
port conditions did not differ significantly (although the means were in this direction). This finding suggests that the nature of the retrieval context may be important for producing the memorial advantage. Finally, the older adults did not benefit more than the young from reinstated elaborations at retrieval, although this finding is difficult to interpret because of floor effects in many of the comparison conditions. Nevertheless, the gains in performance for the old, from .05 in the base condition to .41 in the explanatory-high support condition, are impressive, suggesting that both the quality and presence of elaborations in the encoding and retrieval environments may be important for enhancing older persons' retention of verbal information.

\section{EXPERIMENT 1B}

In Experiment 1B, an intentional learning procedure was used. If the positive effect of explanatory elaborations on memory is limited to incidental learning conditions as Pressley et al. (1987) have argued, then recall performance would not be expected to vary across elaboration conditions. Alternatively, if the effect depends on the compatibility of the encoding and retrieval contexts as the results of Experiment 1A suggest, then the explanatory elaboration effect should emerge in the high retrieval support conditions, and the magnitude of the effect may be relatively greater for the older adults. The intentional learning task was also expected to bolster older adults' performance and thus provide a more sensitive test of the environmental support hypothesis.

\section{Method}

Participants. In all, 120 subjects participated in the study; 60 University of Georgia undergraduates ( $M=19.1$ years, $S D=1.3$ years) and 60 community-dwelling older adults $(M=70.8$ years, $S D=6.0$ years). Younger subjects were sampled from the source used in Experiment 1A. Most of the older adults (40) were from the same North Florida community: the others (20) were recruited from the local church groups and civic organizations in Athens, Georgia, and were tested equally often across conditions. All subjects were compensated for their participation as in Experiment 1A. Most rated their health as "good" or "excellent," 2 young and 5 older adults rated their health as "fair," and 1 young and 1 older adult rated their health as "poor." The older adults' mean score on the verbal measure (21.5) was significantly greater than the younger adults' score $(14.4)[t(118)=8.05]$. All subjects possessed 20/30 corrected visual acuity or better.

Materials, Procedure, and Design. The stimulus sets from Experiment $1 \mathrm{~A}$ were used in this study. The procedure was similar, except that an intentional learning procedure was used: the subjects were told to study the sentences in preparation for a memory test. In the practice task, the same elaborations were reinstated at retrieval across all experimental conditions to ensure that the subjects would encode the elaborations during acquisition. The acquisition, distractor, and retrieval tasks were then given, following the procedures described in Experiment $1 \mathrm{~A}$.

\section{Results}

For each subject, the proportion of adjectives correctly recalled was calculated and entered into an ANOVA with age and elaboration condition as factors. This analysis yielded significant main effects of age $[F(1,110)=36.45$,
$\left.M S_{\mathrm{e}}=.03\right]$ and elaboration condition $[F(4,110)=35.34$, $\left.M S_{\mathrm{e}}=.03\right]$. Younger adults (.41) recalled more adjectives than did elderly adults (.21), and recall was highest in the explanatory elaborations-high retrieval support condition (.67), followed by the arbitrary elaborations-high support (.33), base sentence (.24), explanatory elaborations-low support (.16), and arbitrary elaborations-low support conditions (.14). Pairwise comparisons indicated that recall was significantly greater in the explanatory elaborations-high support condition than in the four comparison conditions. Recall was significantly greater in the arbitrary elaborations-high support condition than in the arbitrary and explanatory elaborations-low support conditions. None of the other pairwise comparisons approached significance.

Inspection of Table 2 reveals that the absolute proportion of adjectives recalled by elderly adults in the base, arbitrary-low support and explanatory-low support conditions was somewhat low; therefore, a one-way ANOVA was conducted on the younger adults' recall scores. The main effect of elaboration condition was significant $[F(4,55)$ $=13.55, M S_{\mathrm{e}}=.04 \mathrm{]}$, and the same pattern of significant pairwise differences was obtained. For the young adults, performance was somewhat greater in the base condition (.38) than in both the arbitrary-low support (.22) and the explanatory-low support (.21) conditions, although these differences were both nonsignificant $(p s<.07)$. Nevertheless, the direction of these pairwise differences implies that varying the presence of elaborations only at encoding (which results in a mismatch between encoding and retrieval contexts) may actually disrupt memory performance for younger adults.

A follow-up ANOVA (less the base sentence condition) yielded significant main effects of age $[F(1,88)=25.39$, $\left.M S_{\mathrm{e}}=.03\right]$, elaboration type $\left[F(1,88)=24.97, M S_{\mathrm{e}}=\right.$ $.03]$, and retrieval support $\left[F(1,88)=97.80, M S_{\mathrm{e}}=.03\right]$. Younger adults $(.42)$ recalled more items than the older adults (.24) did, recall was higher with explanatory elaborations (.41) than with arbitrary elaborations (.24), and recall was greater in the high support (.50) than in the low support conditions (.15). The elaboration type $\times$ retrieval support interaction was also significant $[F(1,88)=$ $\left.20.58, M S_{e}=.03\right]$. The form of this interaction replicated the results of Experiment 1A. Analyses of simple

Table 2

Mean Proportion of Adjectives Recalled, With Standard Deviations, as a Function of Age and Elaboration Type in Experiment 1B

\begin{tabular}{|c|c|c|c|c|c|c|}
\hline \multirow[b]{3}{*}{ Age } & \multirow{2}{*}{\multicolumn{2}{|c|}{ Base }} & \multicolumn{4}{|c|}{ Elaboration Type } \\
\hline & & & \multicolumn{2}{|c|}{ Arbitrary } & \multicolumn{2}{|c|}{ Explanatory } \\
\hline & $M$ & $S D$ & $M$ & $S D$ & $M$ & $S D$ \\
\hline \multicolumn{7}{|c|}{ Low Retrieval Support } \\
\hline Young & .38 & .24 & .22 & .13 & .21 & .15 \\
\hline Old & .11 & .12 & .06 & .09 & .10 & .11 \\
\hline \multicolumn{7}{|c|}{ High Retrieval Support } \\
\hline Young & & & .47 & .29 & .76 & .19 \\
\hline Old & & & .20 & .16 & .59 & .20 \\
\hline
\end{tabular}


main effects confirmed that the proportion correct was greater in the explanatory elaborations-high support condition (.67) than in the arbitrary-high support condition (.33). The means for the arbitrary- and explanatory-low retrieval support conditions did not significantly differ (.14 and .16 , respectively).

\section{Discussion}

The results of this experiment were quite similar to those of Experiment 1A, except that the absolute levels of recall were higher. In the Stein replication conditions (young adults in the low retrieval support conditions), explanatory elaborations only at encoding did not enhance younger adults' performance beyond that in the base sentence and arbitrary-low support conditions. Furthermore, the significant elaboration type $\times$ retrieval support interaction in the follow-up analysis replicated the results of Experiment $1 \mathrm{~A}$. This interaction confirmed that the explanatory elaborations enhanced memory when they were reinstated at retrieval, but there was very little difference in recall in the arbitrary and explanatory conditions with low retrieval support. Finally, the explanatory elaborations did

Table 3

Summary of Previous Research in the Stein Paradigm

\begin{tabular}{|c|c|c|c|}
\hline Study & Materials* & Subjects & Results $\uparrow$ \\
\hline Franks et al. (1982, Experiment 1) & passages (2) & $\begin{array}{l}\text { academically successful/ } \\
\text { less successful 5th graders }\end{array}$ & precise $>$ base \\
\hline $\begin{array}{l}\text { Stein, Bransford, Franks, } \\
\text { Owings, et al. (1982) }\end{array}$ & sentences (8) & less successful 5 th graders & $\begin{array}{l}\text { (self-generated elaborations) } \\
\text { precise }>\text { imprecise }\end{array}$ \\
\hline $\begin{array}{l}\text { Stein, Bransford, Franks, } \\
\text { Vye, \& Perfetto (1982) }\end{array}$ & sentences $(10)$ & less successful 5th graders & precise $>$ imprecise \\
\hline Stein et al. (1978) & sentences (12) & undergraduates & precise $>$ imprecise \\
\hline Stein \& Bransford (1979) & sentences $(10)$ & undergraduates & precise $>$ imprecise \\
\hline Stein et al. (1987) & $\begin{array}{l}\text { sentences (10) } \\
\text { w/illustrations }\end{array}$ & undergraduates & $\begin{array}{l}\text { precise }>\text { imprecise } \\
\text { w/explanatory pictures }\end{array}$ \\
\hline Stein et al. (1984) & sentences $(10)$ & undergraduates & precise $>$ imprecise \\
\hline $\begin{array}{l}\text { Hashtroudi et al. (1989) } \\
\text { undergraduates } \\
\text { older adults } \\
\text { undergraduates } \\
\text { older adults }\end{array}$ & sentences $(12)$ & undergraduates/older adults & $\begin{array}{l}\text { (experimenter provided elaborations) } \\
\text { precise }>\text { base } \\
\text { precise }=\text { base } \\
\text { (self-generated elaborations) } \\
\text { precise }>\text { base } \\
\text { precise }>\text { base }\end{array}$ \\
\hline Pressley et al. (1987) & sentences (24) & undergraduates & $\begin{array}{l}\text { (experimenter provided elaborations) } \\
\text { precise }=\text { base } \\
\text { (self-generated elaborations) } \\
\text { precise }>\text { base }\end{array}$ \\
\hline $\begin{array}{l}\text { Rankin \& Collins (1985) } \\
\text { free recall } \\
\text { cued recall } \\
\text { (elaborations at retrieval) }\end{array}$ & sentences (39) & undergraduates/older adults & $\begin{array}{l}\text { precise }=\text { imprecise } \\
\text { precise }>\text { imprecise }\end{array}$ \\
\hline \multicolumn{4}{|l|}{ Present studies } \\
\hline $\begin{array}{l}\text { Experiment } 1 \mathrm{~A} \\
\text { low retrieval support } \\
\text { high retrieval support }\end{array}$ & sentences (28) & undergraduates/older adults & $\begin{array}{l}\text { explanatory }=\text { base } \\
\text { explanatory }>\text { base } \\
\text { explanatory }>\text { arbitrary }\end{array}$ \\
\hline $\begin{array}{l}\text { Experiment } 1 \mathrm{~B} \\
\text { low retrieval support } \\
\text { high retrieval support }\end{array}$ & sentences $(28)$ & undergraduates/older adults & $\begin{array}{l}\text { explanatory }=\text { base } \\
\text { explanatory }>\text { base } \\
\text { explanatory }>\text { arbitrary }\end{array}$ \\
\hline $\begin{array}{l}\text { Experiment } 2 \\
\text { high encoding support } \\
\text { high retrieval support } \\
\text { high encoding/retrieval support }\end{array}$ & sentences (12) & undergraduates/older adults & $\begin{array}{l}\text { explanatory }=\text { base } \\
\text { explanatory }=\text { base } \\
\text { explanatory }>\text { base }\end{array}$ \\
\hline $\begin{array}{l}\text { Experiment } 3 \\
\text { Present stimuli: } \\
\text { high encoding support } \\
\text { high encoding/retrieval support } \\
\text { Stein stimuli: }\end{array}$ & sentences $(10)$ & undergraduates only & $\begin{array}{l}\text { explanatory }=\text { base } \\
\text { explanatory }>\text { base }\end{array}$ \\
\hline $\begin{array}{l}\text { high encoding support } \\
\text { high encoding/retrieval support }\end{array}$ & & & $\begin{array}{l}\text { explanatory }>\text { base } \\
\text { explanatory }>\text { base }\end{array}$ \\
\hline
\end{tabular}

*Number of stimuli is given in parentheses. †The precise/imprecise distinction is analogous to the explanatory/arbitrary elaboration distinction. 
not differentially enhance older adults' performance. The performance of both age groups was equally facilitated by the explanatory elaborations at encoding and retrieval.

Experiments $1 \mathrm{~A}$ and $\mathrm{IB}$ may have been insensitive to the positive effects of explanatory elaborations only at encoding because a larger number of sentences (28) were used in these studies, whereas Stein and his colleagues used fewer sentences (10). Indeed relatively small stimulus sets have been used in virtually all the prior studies that have yielded a beneficial effect of explanatory elaborations present only at encoding on memory. Table 3 presents a general summary of selected findings from prior work in this area to illustrate this point.

Experiment 2 was conducted to determine whether the positive effect of explanatory elaborations only at encoding would emerge with a smaller set of stimuli, more closely approximating the Stein conditions. An incomplete factorial design had been used in Experiments 1A and 1B, omitting the condition with elaborations at retrieval only. As a result, the independent effect of explanatory elaborations on subjects' retrieval processes was unclear. A completely crossed factorial design was used in Experiment 2 to determine whether older people would benefit more than the young from the elaborations at retrieval only, and to rule out the possibility that the positive effect of explanatory elaborations at encoding and retrieval in Experiments 1A and 1B was due to subjects' making more successful guesses when the elaborations were reinstated at retrieval.

\section{EXPERIMENT 2}

\section{Method}

Participants. In all, 128 subjects participated in the study. There were 64 Louisiana State University undergraduates $(M=20.7$ years, $S D=2.2$ years) and 64 community-dwelling older adults ( $M=68.2$ years, $S D=6.3$ years). The older adults were recruited from local church groups and civic organizations in Baton Rouge, Louisiana. The subjects were compensated for their participation as in Experiments 1A and 1B. Most of the subjects rated their health as "good" and "excellent," and 4 young and 8 older adults rated their health as "fair." Older adults' mean score on the verbal measure (19.3) exceeded the younger adults' score $(12.8)$, a significant difference $[t(121)=6.55]$. All subjects possessed $20 / 30$ corrected visual acuity or better.

Materials, Procedure, and Design. Twelve base sentences with matching explanatory elaborations were randomly chosen from the stimulus set used in Experiments 1 A and 1B. Forty undergraduate students not participating in the experiment proper provided normative data on the probability of correctly guessing the target adjectives, given the sentences without prior study. Half these subjects were presented with base sentences, and the other half studied the same base sentences with matching explanatory elaborations (without the target adjective). The sentences were presented individually, and the subjects were told to guess the missing adjective. None of the target adjectives were correctly guessed for the base sentences, and the mean proportion of correct completions for the explanatory elaboration sentences was less than .01. Thus, it seems doubtful that performance in the experiment proper might be confounded by successful guessing strategies at retrieval.

The incidental learning task and general procedures used in this study were identical to those in Experiment $1 \mathrm{~A}$. The design was a 2 (age) $\times 2$ (encoding support) $\times 2$ (retrieval support) between- group factorial. This design was used to assess the independent effects of elaborations on young and older adults' encoding and retrieval processes. For convenience, low support refers to the base sentence contexts and high support refers to the base sentences with explanatory elaborations. Sixteen subjects were tested in each between-group condition.

\section{Results}

The proportion of adjectives correctly recalled was calculated for each subject. Scores were entered into an ANOVA, with age, encoding support, and retrieval support as between-group factors. The means appear in Table 4 . This analysis yielded significant main effects of age, encoding support and retrieval support. The younger adults $(.46)$ recalled more items than did the older adults $(.28)\left[F(1,120)=23.97, M S_{e}=.04\right]$; recall was greater in the high encoding support condition (.42) than in the low encoding support condition $(.32)[F(1,120)=7.27$, $\left.M S_{\mathrm{e}}=.04\right]$; and recall was greater in the high retrieval support condition $(.45)$ than in the low retrieval support condition $(.28)\left[F(1,120)=21.93, M S_{\mathrm{e}}=.04\right]$. The encoding support $\times$ retrieval support interaction was also significant $\left[F(1,120)=8.46, M S_{\mathrm{e}}=.04\right]$. Pairwise comparisons confirmed that the presence of elaborations at encoding and retrieval enhanced recall performance more than did the three comparison conditions, which did not significantly differ-as the means in Table 4 suggest. There were no other significant interactions in this analysis.

The age $x$ encoding support $\times$ retrieval support interaction did not approach significance. Nevertheless, the pattern of pairwise differences is consistent with the environmental support hypothesis. That is, the mean age difference in recall was minimal in the high encoding/high retrieval support condition, and relatively greater in the three comparison conditions. Pairwise comparisons confirmed that in the low encoding/low retrieval and low encoding/high retrieval support conditions, significant age differences occurred, with mean age differences favoring the young of .22 and .23 , respectively $(p=.05)$. The mean age difference was marginally significant for the high encoding/low retrieval support condition (mean difference of $.22, p=.06$ ). Most importantly, the young and older adults' performance did not significantly differ

Table 4

Mean Proportion of Adjectives Recalled, With Standard Deviations, as as a Function of Age, Encoding, and Retrieval Support in Experiment 2

\begin{tabular}{lllll}
\hline & \multicolumn{4}{c}{ Retrieval Condition } \\
\cline { 2 - 3 } & \multicolumn{2}{c}{ Low Support } & High Support \\
\cline { 2 - 3 } Encoding Condition & $M$ & $S D$ & $M$ & $S D$ \\
\hline Low Support & & & & \\
$\quad$ Young & .40 & .23 & .46 & .24 \\
$\quad$ Old & .17 & .15 & .23 & .20 \\
$M$ & .28 & & .35 & \\
High Support & & & & \\
$\quad$ Young & .39 & .20 & .58 & .30 \\
Old & .17 & .13 & .53 & .17 \\
$M$ & .28 & & .56 & \\
\hline
\end{tabular}


in the high encoding/high retrieval support condition, with a mean age difference of $.05(p=.9)$.

\section{Discussion}

The results of Experiment 2 confirmed that explanatory elaborations at encoding and retrieval enhanced recall for young and older adults. The significant encoding $X$ retrieval support interaction replicates the results of Experiments $1 \mathrm{~A}$ and $1 \mathrm{~B}$, so the effect appears to be reliable. A more interesting aspect of the data was that agerelated differences in recall were nonsignificant when the explanatory elaborations were present during encoding and retrieval and that comparatively larger differences were obtained under conditions of less encoding and/or retrieval support. This pattern of findings confirms the environmental support hypothesis (Craik, 1986; Craik et al., 1987) and is consistent with earlier research showing that age-related differences on cognitive tasks are minimal when supportive tasks and materials are used (see Cherry \& Park, 1991; Craik \& McDowd, 1987; Shaw \& Craik, 1989).

There was no evidence to suggest that elaborations at only encoding enhanced recall. The design used in this study permitted an independent assessment of the effects of explanatory elaborations on encoding and retrieval processes. These results suggest that for elaborations to be most useful for memory, they should be present during both encoding and retrieval. Contrary to our expectation, the original Stein effect was not replicated when a smaller stimulus set was used. A comparison of the present stimuli and procedures with those in the earlier Stein reports reveals that a number of key differences may be responsible for the failure to replicate the Stein et al. results (Stein \& Bransford, 1979; Stein et al., 1984; Stein et al., 1978) in the elaborations only at encoding condition. The explanatory elaboration effect described by Stein and his associates may depend on the materials presented for study. Alternatively, the procedure that Stein used may be the critical variable, or perhaps an interaction of these two variables is essential for the effect to emerge. Experiment 3 was conducted to systematically examine these possibilities. We factorially crossed Stein et al.'s (1987) procedure with the present procedure and Stein et al.'s sentences with the present sentences to more precisely specify the conditions under which the original Stein effect might emerge. Only college students were tested in Experiment 3, since the main issues under investigation in this experiment were nondevelopmental.

\section{EXPERIMENT 3}

\section{Method}

Participants. In all, 144 LSU undergraduate students participated for psychology course credit ( $M=20.9$ years, $S D=4.4$ years). Most rated their health as "good" and "excellent," and 7 rated their health as "fair." The mean score on the verbal measure (12.6) was comparable to the younger adults' scores in the other experiments reported here. All subjects possessed 20/30 corrected visual acuity or better.
Materials, Procedure, and Design. The total stimulus set comprised 20 base sentences with matching explanatory elaborations (see Appendix B). There were two sets of 10 sentences. Set 1 contained the original 10 sentences used in Stein et al.'s research (see Stein et al., 1987, p. 290), and Set 2 consisted of 10 sentences randomly selected from the set of 12 sentences used in Experiment 2. Stein et al. 's (1987) stimuli were normed to verify that the explanatory elaborations clarified the subject-adjective relationships more than the base sentence contexts. To determine whether the present sentences are comparable to Stein et al.'s (1987) sentences, the same normative procedure described in Stein et al. (1987) was used. Twenty-two students not participating in the experiment proper were given a response sheet with the 20 sentences in a random order. The subjects were instructed to rate on a scale of 1-5 the degree to which the sentences explained the key reiationship between the particular man and the type of action that he performed $(1=$ the sentence poorly explained the relationship, and $5=$ the sentence clearly explained the relationship between the man and the type of action he performed). The means for the base and explanatory elaboration sentences, in order, were 1.67 and 4.41 , a significant difference $[t(21)=-22.21, p<.001]$. These means are virtually identical to the means in Stein et al. (1987) for the base (1.25) and explanatory elaboration sentences (4.65), suggesting that the explanatory elaborations in Experiment 3 were equally effective in clarifying the significance of the subject-adjective relationships in the base sentences.

Half the subjects in Experiment 3 were tested with the procedure described in Stein et al. (1987) and the other half were tested with the same general procedure as that in Experiments $1 \mathrm{~A}$ and 2. Both procedures used incidental learning instructions. For those tested under Stein et al.'s procedure (Procedure 1), the experimenter read each sentence aloud and paused for $7 \mathrm{sec}$ while the subjects judged the sentence for comprehensibility. The subjects rated each sentence for how easy or difficult the sentence was to comprehend on a 5-point scale $(1=$ easy to understand, $5=$ difficult to understand). Following acquisition, a 45-sec distractor task was given, in which the subjects were told to mentally count backwards from 500 by threes. At test, the experimenter read each of the 10 base sentences (without the critical adjective) or the same base sentences with explanatory elaborations, depending on the experimental condition, pausing for $5 \mathrm{sec}$ after each sentence while the subjects recorded their responses. The general procedure described in Experiment $1 \mathrm{~A}$ was used for those tested in the present procedure (Procedure 2).

Table 5

Mean Proportion of Adjectives Recalled, With Standard Deviations, as a Function of Stimulus Set, Procedure, and Encoding/Retrieval Support in Experiment 3

\begin{tabular}{|c|c|c|c|c|}
\hline \multirow{3}{*}{$\begin{array}{l}\text { Encoding/Retrieval } \\
\text { Support Condition }\end{array}$} & \multicolumn{4}{|c|}{ Stimulus Set } \\
\hline & \multicolumn{2}{|c|}{ 1* } & \multicolumn{2}{|c|}{$2+$} \\
\hline & $M$ & $S D$ & $M$ & $S D$ \\
\hline \multicolumn{5}{|c|}{ Procedure $1 \ddagger$} \\
\hline Low/low & .22 & .19 & .34 & .12 \\
\hline High/low & .61 & .27 & .29 & .28 \\
\hline High/high & .67 & .18 & .52 & .25 \\
\hline \multicolumn{5}{|c|}{ Procedure $2 \S$} \\
\hline Low/low & .45 & .17 & .49 & .22 \\
\hline High/low & .56 & .22 & .34 & .27 \\
\hline High/high & .78 & .28 & .61 & .29 \\
\hline
\end{tabular}

*Stimulus Set $1=10$ original Stein sentences. † Stimulus Set $2=10$ of the sentences used in Experiments $1 \mathrm{~A}, 1 \mathrm{~B}$, and 2. \$Procedure $1=$ original Stein incidental learning procedure. \$Procedure $2=$ incidental learning procedure used in Experiments $1 \mathrm{~A}$ and 2. 
The design was a $2 \times 2 \times 3$ factorial with experimental procedure (Procedure I vs. Procedure 2), stimulus set (Set 1 vs. Set 2), and encoding/retrieval support (low encoding/low retrieval; high encoding/low retrieval; high encoding/high retrieval support) as betweengroup factors. Twelve subjects were tested in each between-group condition.

\section{Results and Discussion}

The proportion of adjectives correctly recalled was entered into an ANOVA with procedure, stimulus set, and encoding/retrieval support condition as factors. The means are presented in Table 5. The results of this ANOVA yielded significant main effects of procedure, stimulus set, and encoding/retrieval support condition. The present procedure resulted in better recall (.54) than Stein et al.'s (1987) original procedure did $(.44)[F(1,132)=6.17$, $\left.M S_{\mathrm{e}}=.06\right]$; Stein et al.'s (1987) stimuli (.55) were remembered better than the present stimuli $(.43)$ were $\left[F(1,132)=8.47, M S_{\mathrm{e}}=.06\right] ;$ and consistent with the results of the three preceding experiments, recall was greatest in the high encoding/high retrieval support condition (.64), followed by the high encoding/low retrieval support (.45) and low encoding/low retrieval support (.38) conditions $\left[F(2,132)=16.47, M S_{\mathrm{e}}=.06\right]$. The encoding/retrieval support $\times$ stimulus set interaction was also significant $\left[F(2,132)=6.99, M S_{e}=.06\right]$. Pairwise comparisons confirmed that when the stimuli from Stein et al. were used, recall in the high encoding/low retrieval support condition (.58) was significantly greater than that in the low encoding/low retrieval support condition (.33), replicating the results of Stein's earlier work. Performance with explanatory elaborations only at encoding did not significantly differ from that in the high encoding/high retrieval support condition (.72) $(p=.3)$, although the direction of the means is compatible with the general pattern of results obtained in the experiments reported here.

Pairwise comparisons also confirmed that when the present stimuli were used, recall performance in the high encoding/low retrieval support condition (.32) did not significantly differ from that in the low encoding/low retrieval support condition (.42) $(p=.7)$, but that it was exceeded by performance in the high encoding/high retrieval support condition $(.56, p=.005)$; this was consistent with the results of Experiments 1A, 1B, and 2. In sum, the form of the significant interaction effect confirms the results of the present experiments and replicates the earlier work of Stein and his associates. That is, explanatory elaborations present only at encoding enhanced recall more than did the base sentences alone when Stein et al.'s (1987) stimuli were presented, but not when the present stimuli were used. This aspect of the data suggests that, under some circumstances, explanatory elaborations may have a positive effect on memory that is independent of encoding specificity effects. However, our results indicate that the generality of this effect may be more limited than previous research would suggest, since the advantage of experimenter-provided elaborations at encoding was obtained only when the Stein stimuli were used.

\section{GENERAL DISCUSSION}

The principal new findings that emerge from these experiments can be summarized as follows. First, the results indicated that explanatory elaborations at encoding and retrieval enhanced memory for target adjectives in young and older adults. Second, when subjects were given a relatively short set of sentences, adult age differences in recall were minimal with explanatory elaborations at encoding and retrieval. Larger differences were obtained under conditions of comparatively less encoding and/or retrieval support, confirming the environmental support hypothesis. Third, when the original sentences from Stein et al. (1987) were used, elaborations only at encoding enhanced recall more than did base sentence contexts for younger adults, replicating the Stein et al.'s earlier results. These findings are discussed in detail below.

The first finding of interest was that explanatory elaborations present during encoding and retrieval had a positive effect on recall performance. This result was obtained under incidental (Experiments 1A, 2, and 3) and intentional (Experiment $1 \mathrm{~B}$ ) learning conditions, and with relatively long (Experiments 1A-1B) and short (Experiments 2-3) acquisition lists, suggesting that the effect is quite reliable. Across four experiments, explanatory elaborations enhanced recall as expected, but for the most part, this result occurred only when the elaborations were reinstated at retrieval (see Fisher, 1981, and Fisher \& Craik, 1980 , for a similar finding). Explanatory elaborations at encoding but not retrieval enhanced recall for the young only when Stein et al.'s (1987) original stimuli were used, as discussed later. The pattern of results reported here is generally compatible with Stein's viewpoint, and these findings appear to resolve the conflicting data from Pressley et al. (1987).

The results of Experiments $1 \mathrm{~A}$ and $1 \mathrm{~B}$ show that explanatory elaborations enhanced retention more than arbitrary elaborations did, in the high retrieval support conditions for young and elderly adults. This is an important finding, suggesting that the semantic content of the verbal elaborations alone was not sufficient for producing the memorial advantage. For elaborations to be most effective, it appears that they must clarify the significance of the subject-adjective relationship, as Stein has suggested (Stein \& Bransford, 1979; Stein et al., 1984; Stein et al., 1978). At odds with Stein, however, was the finding that the memorial benefit was seldom obtained in the low retrieval support conditions, where only the base sentence contexts served as prompts for recall. This outcome was puzzling, since these conditions were modeled after Stein et al.'s (Stein \& Bransford, 1979; Stein et al., 1984; Stein et al., 1978) research.

Pressley et al. (1987) also found only a slight memorial advantage of experimenter-provided explanatory elaborations on incidental memory, and no advantage was obtained for intentional memory performance in their studies. Consequently, Pressley et al. argued that the benefit of explanatory elaborations on memory may be quite 
fragile and limited to conditions in which learning occurs incidentally. In Pressley et al.'s research, only base sentence contexts were used as retrieval cues-a format similar to the low retrieval support conditions in the present research. Our findings in the low retrieval support conditions are quite consistent with Pressley et al.'s results, the one exception being that experimenter-provided explanatory elaborations only at encoding had a very modest effect on incidental memory performance in Pressley et al., as previously discussed. The issue to be resolved, then, is why Stein and his associates have consistently found a robust advantage of explanatory elaborations only at encoding on memory performance, and why similar outcomes were not obtained in Pressley et al.'s report and in the low retrieval support conditions in this research.

One explanation for the conflicting results, addressed in Experiment 2, concerned the differences in stimulus set sizes used in previous research in the Stein paradigm (see Table 3). Stein and his associates presented short lists of sentences for study and test. Relatively longer lists were used in Experiments 1A and 1B and in Pressley et al.'s (1987) studies, which may have reduced the salience of the target adjectives in memory, attenuating recall performance when there were elaborations only at encoding. The results of Experiment 2 provided little evidence to confirm this notion. Recall with elaborations only at encoding was comparable to recall in the base sentence condition when fewer sentences were presented, an outcome which is the same as that in Experiments 1A and 1B. Contrary to our expectation, the positive effect of explanatory elaborations only at encoding on memory does not appear to depend on the number of stimuli presented during acquisition and retrieval. The results of Experiment 3 suggest that this effect appears to be controlled by properties of the stimuli, as discussed below.

The more interesting aspect of the data from Experiment 2 was the finding that magnitude of age-related differences in recall varied as a function of elaboration condition. Specifically, young and older adults' performance was comparable (a nonsignificant difference) when the explanatory elaborations were provided as support for encoding and retrieval processes, but significant age differences occurred in the conditions that provided less encoding and/or retrieval support. The finding that the magnitude of age-related differences in recall was reduced with elaborations present during encoding and retrieval is important, because this result confirms the environmental support hypothesis (cf. Craik et al., 1987; Craik \& Jennings, 1992), and joins other results in the cognitive aging literature that have corroborated the environmental support view of memory aging in other verbal recall paradigms (Bäckman \& Karlsson, 1986; Craik et al., 1987; Rabinowitz, 1986; Shaw \& Craik, 1989). The failure to find evidence of a special mnemonic benefit of explanatory elaborations at encoding and retrieval for older persons in Experiments 1A and 1B and in Rankin and Collins (1985) was likely due to insensitivity in the experimental measures, since the older adults' performance was approaching floor in the comparison conditions in these studies. One could argue that relatively long acquisition lists (as in Experiments $1 \mathrm{~A}$ and $1 \mathrm{~B}$ and in Rankin \& Collins, 1985) increase the processing demands at encoding and retrieval, resulting in poorer performance for older adults who experience age-related declines in many component processes of cognition (see Salthouse, 1991). In Experiment 2, the processing demands associated with the task were lessened by presenting fewer sentences at study and test, and older persons retained amounts of sentential information similar to those for younger persons with the explanatory elaborations present during encoding and retrieval. With an eye toward everyday memory practice, then, the findings of Experiment 2 suggest that verbal elaborations in the encoding and retrieval environments may be particularly useful for promoting retention of sentential material in older people, provided that the number of stimuli presented does not substantially increase the task-related processing demands for older adults.

The third major finding of interest in this research was that elaborations only at encoding enhanced younger adults' recall more than the base sentence context did, when Stein et al.'s (1987) original stimuli were presented but not when our stimuli were used. The significant encoding/retrieval support $\times$ stimulus set interaction in Experiment 3 yields new evidence that clarifies the limiting conditions under which elaborations in the encoding environment enhance recall for younger adults. To provide further insight into possible reasons for this unexpected outcome, post hoc comparisons were made between the present stimuli and the stimuli from Stein et al. Specifically, our target adjectives were lower in the frequency of occurrence in spoken language than were Stein et al.'s stimuli. ${ }^{1}$ Our target adjectives also appear to be morphologically more complex than Stein et al.'s stimuli (e.g., grimacing vs. fat). Our sentences and Stein et al.'s sentences were not equated for syntactic complexity, and differences in the overall quality of the elaborations may possibly account for the different results obtained. We have suggested some possible reasons why the memorial benefit of elaborations at encoding but not retrieval was obtained only when Stein et al.'s stimuli were used. One direction for future research in this paradigm would be to systematically examine the interactive relationship between the stimulus characteristics of the target adjectives and the syntactic features and quality of the sentence contexts to foster a more complete understanding of the mnemonic efficacy of verbal elaborations.

In summary, these results have shown that explanatory elaborations present during encoding and retrieval enhance recall for young and older adults. The mnemonic efficacy of verbal elaborations present only at encoding appears to be less consistent than the earlier Stein et al. (Stein \& Bransford, 1979; Stein et al., 1984; Stein et al., 1978) studies would suggest, in agreement with Pressley et al. (1987). Regarding practical significance, these results suggest that persons who attempt to learn a rather substantial quantity of new and seemingly arbitrary information, which is likely in formal educational settings, may benefit from the presence of explanatory elaborations, pro- 
vided that the elaborations are available to the learner both during acquisition and attempts at retrieval.

\section{REFERENCES}

BÄCKMAN, L., \& KARLSSON, T. (1986). Episodic remembering in young adults, 73 year olds, and 82 year olds. Scandinavian Journal of Psychology, 27, 320-325.

Bransford, J. D., Stein, B. S., Vye, N. J., Franks, J. J., Auble, P. M., Mezynski, K. J., \& Perfetto, G. A. (1982). Differences in approaches to learning: An overview, Journal of Experimental Psychology: General, 111, 390-398.

Cherry, K. E., PARK, D. C. (1991, August). Contextual influences on direct and indirect memory in older adults. Paper presented at the meeting of the American Psychological Association, San Francisco.

Craik, F. I. M. (1983). On the transfer of information from temporary to permanent memory. Philosophical Transactions of the Royal Society of London (Series B), 302, 341-359.

Craik, F. I. M. (1986). A functional account of age differences in memory. In F. Klix \& H. Hagendorf (Eds.), Human memory and cognitive capabilities: Mechanisms and performances (pp. 409-422). Amsterdam: Elsevier.

Craik, F. I. M., Byrd, M., Swanson, J. M. (1987). Patterns of memory loss in three elderly samples. Psychology \& Aging, 2, 79-86.

Craik, F. I. M., Jennings, J. M. (1992). Human memory. In F. I. M. Craik \& T. A. Salthouse (Eds.), The handbook of aging and cognition (pp. 51-110). Hillsdale, NJ: Erlbaum.

CRAIK, F. I. M., MCDOWD, J. (1987). Age differences in recall and recognition. Journal of Experimental Psychology: Learning, Memory, \& Cognition, 13, 474-479.

Duke Universtty Center for the Study of Aging and Human DeVELOPMENT. (1975). OARS: Multidimensional Functional Assessment Questionnaire. Durham, NC: Duke University.

FiSHER, R. P. (1981). Interaction between encoding distinctiveness and test conditions. Journal of Experimental Psychology: Human Leaming \& Memory, 7, 306-310.

Fisher, R. P., \& Craik, F. I. M. (1980). The effects of elaboration on recognition memory. Memory \& Cognition, 8, 400-404.

Franks, J. J., Vye, N. J., Auble, P. M., Mezynski, K. J., Perfetto, G. A., Bransford, J. D., Stein, B. S., \& LitTlefield, J. (1982). Learning from explicit versus implicit texts. Journal of Experimental Psychology: General, 111, 414-422.

Gardner, E., Monge, R. (1977). Adult age differences in cognitive abilities and educational background. Experimental Aging Research, 8, 337-383.

Hashtroudi, S., Parker, E. S., Luts, J. D., \& Reisen, C. A. (1989). Generation and elaboration in older adults. Experimental Aging Research, 15, 73-78.

Perlmutter, M., \& Mitchell, D. B. (1982). The appearance and disappearance of age differences in adult memory. In F. I. M. Craik \& S. Trehub (Eds.), Aging and cognitive processes (Vol. 8, pp. 127144). New York: Plenum.

Pressley, M., McDaniel, M. A., Turnure, J. E., Wood, E., \& AHMAD, M. (1987). Generation and precision of elaboration: Effects on intentional and incidental learning. Journal of Experimental Psychology: Learning, Memory, \& Cognition, 13, 291-300.

Rabinowitiz, J. C. (1986). Priming in episodic memory. Joumal of Gerontology, 41, 204-213.

Rabinowitz, J. C., Craik, F. I. M., Ackerman, B. P. (1982). A processing resource account of age differences in recall. Canadian Journal of Psychology, 36, 325-344.

RANKIN, J. L., \& ColLINS, M. (1985). Adult age differences in memory elaboration. Journal of Gerontology, 40, 451-458.

SALthouSE, T. A. (1991). Theoretical perspectives on cognitive aging. Hillsdale, NJ: Erlbaum.

Shaw, R. J., CRaIK, F. I. M. (1989). Age differences in predictions and performance on a cued recall task. Psychology \& Aging, 4, 131-135.

SMrth, A. D. (1980). Age differences in encoding, storage, and retrieval. In L. W. Poon, J. L. Fozard, L. S. Cermak, D. Arenberg, \& L. W. Thompson (Eds.), New directions in memory and aging. Hillsdale, NJ: Erlbaum.

STEIN, B. S., \& BRANSFORD, J. D. (1979). Constraints on effective elaboration: Effects of precision and subject generation. Journal of Verbal Learning \& Verbal Behavior, 18, 769-777.

Stein, B. S., Bransford, J. D., Franks, J. J., Owings, R. A., Vye, N. J., McGraw, W. (1982). Differences in the precision of selfgenerated elaborations. Joumal of Experimental Psychology: General, 111, 399-405

Stein, B. S., Bransford, J. D., Franks, J. J., Vye, N. J., \& PerFETTO, G. A. (1982). Differences in judgments of learning difficulty. Journal of Experimental Psychology: General, 111, 406-413.

Stein, B. S., Brock, K. F., Ballard, D. R., Vye, N. J. (1987). Constraints on effective pictorial and verbal elaboration. Memory \& Cognition, 15, 281-290

Stein, B. S., Littlefield, J., Bransford, J. D., \& Persampieri, M. (1984). Elaboration and knowledge acquisition, Memory \& Cognition, 12, 522-529.

Stein, B. S., Morris, C. D., \& Bransford, J. D. (1978). Constraints on effective elaboration. Joumal of Verbal Leaming \& Verbal Behavior, 17, 707-714.

THORNDIKE, E. L., LORGE, I. (1944). The teacher's word book of 30,000 words. New York: Teachers College Press, Columbia University.

Tulving, E., \& Thompson, D. M. (1973). Encoding specificity and retrieval processes in episodic memory. Psychological Review, 80 , 353-373.

\section{NOTE}

1. A post hoc comparison of the frequencies of occurrence in spoken language (Thorndike \& Lorge, 1944) revealed that the Stein et al. (1987) stimuli had higher frequencies of occurrence per million than did the present stimuli. For the Stein et al. items, $60 \%$ of the total stimulus set was rated AA ( 100 or more per million) and $20 \%$ were A ( 50 or more per million). Only $10 \%$ of our stimuli were rated AA and $30 \%$ were $\mathrm{A}$.

\section{APPENDIX A \\ Acquisition Sentences from Experiments 1A, 1B, 2, and 3}

\section{Base Sentences}

1a. The grimacing man held the cheese.

2a. The jumping man slapped his leg.

3a. The wet man carried the pan.

4a. The dusty man held the rope

5a. The smiling man stepped on an envelope.

6a. The robed man held the folder.

7a. The frozen man took the umbrella.

8a. The bald man looked at the floor.

9a. The shaking man held the strap. 
10a. The leaping man grabbed the vine.

11a. The masked man picked up the can.

12a. The squatting man held the wrench.

13a. The sleeping man sat in the chair.

14a. The bearded man walked out of the store.

15a. The bandaged man walked across the lawn.

16a. The running man passed the bush.

17a. The muscular man watched the television.

18a. The windblown man closed the door.

19a. The rigid man took a step.

20a. The crippled man found the branch.

21a. The scratching man stood next to the tree.

22a. The toothless man used the knife.

23a. The fat man read the sign.

24a. The old man stood by the table.

25a. The stretching man looked up.

26a. The handcuffed man walked by the tree.

27a. The short man held the broom.

28a. The blind man held the brush.

\section{Base Sentences With Arbitrary Elaborations}

1b. The grimacing man held the cheese and reached for a cracker.

2b. The jumping man slapped his leg as the school bus passed by.

$3 \mathrm{~b}$. The wet man carried the pan into the garage.

$4 \mathrm{~b}$. The dusty man held the rope and tied the boxes.

$5 b$. The smiling man stepped on an envelope that was next to the trash can.

$6 \mathrm{~b}$. The robed man held the folder with a woman at his side.

7b. The frozen man took the umbrella and swatted a fly on the wall.

$8 \mathrm{~b}$. The bald man looked at the floor where the milk was spilled.

$9 \mathrm{~b}$. The shaking man held the strap while he stood near the wall.

$10 \mathrm{~b}$. The leaping man grabbed the vine and pulled it off of the tree.

$11 \mathrm{~b}$. The masked man picked up the can that was in the cabinet.

12b. The squatting man held the wrench that was near the tool box.

13b. The sleeping man sat in the chair with the puppy at his feet.

14b. The bearded man walked out of the store carrying a garden hose.

15b. The bandaged man walked across the lawn and admired the flowers.

16b. The running man passed the bush near the park bench.

17b. The muscular man watched the television and ate the chips.

18b. The windblown man closed the door and wiped his face.

19b. The rigid man took a step and scratched his head.

20b. The crippled man found the branch that was lying in the grass.

$21 \mathrm{~b}$. The scratching man stood next to the tree where an owl was perched.

22b. The toothless man used the knife to carve a board.

$23 \mathrm{~b}$. The fat man read the sign that said the house was for sale.

24b. The old man stood by the table and lit the candle.

25b. The stretching man looked up and stood on his toes.

26b. The handcuffed man walked by the tree next to the gate.

$27 \mathrm{~b}$. The short man held the broom and swept behind the sofa.

$28 \mathrm{~b}$. The blind man held the brush and took a sip of coffee.

\section{Base Sentences With Explanatory Elaborations}

1c. The grimacing man held the cheese while the mousetrap sprang on his finger.

2c. The jumping man slapped his leg as the hornets flew around him.

$3 c$. The wet man carried the pan which was full of gold.

$4 c$. The dusty man held the rope and lassoed the wild calf.

5c. The smiling man stepped on an envelope that had one hundred dollars in it

$6 \mathrm{c}$. The robed man held the folder and banged the gavel on his desk.

7c. The frozen man took the umbrella and speared a fish through the ice.

8c. The bald man looked at the floor where the barber had shaved his hair.

9c. The shaking man held the strap that was attached to the exercise machine.

$10 \mathrm{c}$. The leaping man grabbed the vine and swung across the river.

11c. The masked man picked up the can and sprayed the poisonous gas. 
12c. The squatting man held the wrench and fixed the pipe under the sink.

13c. The sleeping man sat in the chair beside the hypnotist with a swinging watch.

$14 \mathrm{c}$. The bearded man walked out of the store carrying a can of shaving cream.

15c. The bandaged man walked across the lawn and away from the hospital.

16c. The running man passed the bush and hid the loot from the robbery.

17c. The muscular man watched the television while he lifted weights.

18c. The windblown man closed the door as the tornado whipped down the street.

19c. The rigid man took a step down the street on his stilts.

$20 \mathrm{c}$. The crippled man found the branch and used it as a cane.

21c. The scratching man stood next to the tree where the poison ivy grew.

22c. The toothless man used the knife to carve a set of dentures.

23c. The fat man read the sign that said the ice was thin.

$24 \mathrm{c}$. The old man stood by the table and blew out the candles on the birthday cake.

25c. The stretching man looked up and reached for the cookies on the top shelf.

26c. The handcuffed man walked by the tree to the jail.

$27 \mathrm{c}$. The short man held the broom and used it to flip the switch.

$28 \mathrm{c}$. The blind man held the brush and groomed his seeing eye dog.

Note--Experiments $1 \mathrm{~A}$ and $1 \mathrm{~B}$ used the total stimulus set (i.e., Sentence Sets 1a,b,c-28a,b,c); Experiment 2 used Sentence Sets 1a,c-12a,c; and Experiment 3 used Sentence Sets 1a,c-10a,c.

\section{APPENDIX B \\ Acquisition Sentences from Experiment 3 and the Stein et al. (1987) Sentences}

\section{Base Sentences (Experiment 3)}

1. The grimacing man held the cheese.

2. The jumping man slapped his leg.

3. The wet man carried the pan.

4. The dusty man held the rope.

5. The smiling man stepped on an envelope.

6 . The robed man held the folder.

7. The frozen man took the umbrella.

8. The bald man looked at the floor.

9. The shaking man held the strap.

10. The leaping man grabbed the vine.

Base Sentences (Stein et al., 1987)

1. The short man bought the broom.

2. The old man used the paint.

3. The fat man looked at the warning.

4. The funny man bought a ring.

5. The smart man used the charcoal.

6 . The big-footed man bought some signs.

7. The strong man talked to the woman.

8. The thin man picked up the scissors.

9. The bald man used the telephone.

10. The tall man bought the crackers.

\section{Base Sentences With Explanatory Elaborations (Experiment 3)}

1. The grimacing man held the cheese while the mousetrap sprang on his finger.

2. The jumping man slapped his leg as the hornets flew around him.

3. The wet man carried the pan which was full of gold.

4. The dusty man held the rope and lassoed the wild calf.

5. The smiling man stepped on an envelope that had one hundred dollars in it.

6. The robed man held the folder and banged the gavel on his desk.

7. The frozen man took the umbrella and speared a fish through the ice.

8. The bald man looked at the floor where the barber had shaved his hair.

9. The shaking man held the strap that was attached to the exercise machine.

10. The leaping man grabbed the vine and swung across the river. 
Base Sentences With Explanatory Elaborations (Stein et al., 1987)

1. The short man bought the broom to operate the light switch.

2. The old man used the paint to change the color of his cane.

3. The fat man looked at the warning that said keep off the thin ice.

4. The funny man bought a ring that squirted water.

5. The smart man used the charcoal to write the message when the pen broke.

6. The big-footed man bought some signs that said keep off my feet.

7. The strong man talked to the woman about moving her television set.

8. The thin man picked up the scissors to cut the belt in half.

9. The bald man used the telephone to call about the hat sale.

10. The tall man bought the crackers that were on the top shelf.

(Manuscript received February 11, 1991;

revision accepted for publication June 22,1993 .) 